\title{
COMMENTARY
}

\section{Cardiovascular consequences of cooling in critical care}

\author{
Paul Steendijk* \\ See related research by Filseth et al., http://ccforum.com/content/14/6/R211
}

\begin{abstract}
This commentary discusses a paper by Filseth and colleagues in a previous issue of Critical Care. The authors describe the cardiovascular effects of induced hypothermia, focusing particularly on posthypothermic ventricular function. The findings indicate that the treatment resulted in reduced systolic but unchanged diastolic left ventricular function with compensatory effects on heart rate and systemic vascular resistance. The novel aspects of this study are the registration of ventricular function using sophisticated, load-independent indices in a clinically relevant, large animal model during the entire cooling and re-warming trajectory of hypothermia therapy.
\end{abstract}

In a previous issue of Critical Care, Filseth and colleagues [1] describe the cardiovascular effects of surface cooling towards severe hypothermia $\left(25^{\circ} \mathrm{C}\right)$ and subsequent surface re-warming in an anesthetized, closed-chest pig model, focusing particularly on post-hypothermic ventricular function.

Hypothermia may improve outcome after an ischemic event. Remarkable, anecdotal examples of this phenomenon are known from skiing accidents, winter warfare and other cold, human pastimes. In medicine, intentional use of controlled hypothermia has a long history. Presumably, the most widely used and accepted therapeutic applications are cooling to enable procedures with prolonged ischemia, such as open heart surgery, organ preservation and transplantation. In planned surgery, hypothermia is typically induced as a protective strategy before the start of ischemia. Currently, however, the efficacy of hypothermia as an emergency treatment during ongoing ischemia or reperfusion in cases such as

*Correspondence: p.steendijk@lumc.nl

Department of Cardiology, Leiden University Medical Center, PO Box 9600, 2300 RC, Leiden, The Netherlands stroke, myocardial infarction, and cardiac arrest is receiving much attention. Randomized clinical trials have demonstrated that treatment with moderate hypothermia improves survival and neurological outcome in unconscious patients after resuscitation from out-ofhospital cardiac arrest [2,3]. As a result, recent American and European guidelines recommend the induction of therapeutic hypothermia for comatose cardiac arrest survivors $[4,5]$. Research has importantly focused on hypothermia as a neuroprotective strategy and a wide range of pathways that might be involved in the beneficial effects of cooling has been described. The basic theory is that hypothermia slows down cellular metabolism and oxygen demand and thereby reduces the harmful acute and delayed effects of oxygen deprivation. Hypothermia attenuates ischemia-induced free radical production, and abnormalities in cellular calcium handling and $\mathrm{pH}$ balance [6]. Furthermore, hypothermia may target more delayed cell death processes by affecting inflammatory signaling and apoptotic pathways [7]. In principle, these protective mechanisms apply not only to the brain but also to the heart (and other organs, for that matter). However, in contrast to rather convincing animal data [8], clinical studies aiming to determine whether hypothermia limited infarct size in patients with ST segment elevation myocardial infarction (STEMI) undergoing percutaneous revascularization [9] or in survivors of cardiac arrest [10] did not clearly establish such an effect.

In addition to the pursued protective effects, hypothermia induces important physiological changes, or side effects, in almost every organ system. These changes partly result from physiological thermoregulatory reflexes aimed at decreasing heat loss and restoring normal temperature, such as sympathetic activation, cutaneous vasoconstriction, and shivering. More generally, enzyme kinetics are temperature-dependent and thus, in principle, all enzyme-mediated reactions, including drug metabolism, are affected by hypothermia. The direct effect of temperature per se on myocardial function has been the subject of various previous studies. Basic in vitro studies in muscle strips from healthy myocardium have shown substantially increased contractility (measured as 
isometric twitch force) and prolonged contraction and relaxation times with mild hypothermia [11]. Recently, studies in isolated failing human myocardium have shown very similar results [12]. Despite a prolonged action potential, these effects seem not to be associated with increased sarcoplasmatic reticulum calcium content or altered calcium transients, suggesting that increased calcium responsiveness of the myofilaments is the main mechanism for the observed increased inotropism. Consistent with these findings, intact animal studies with mild hypothermia have shown increased systolic function, resulting in increased cardiac output despite reduced heart rate, whereas vascular resistance was generally reported to be relatively unaffected [11]. In contrast, however, in some clinical studies increased vascular resistance was reported to dominate and lead to a reduced cardiac output [3]. Differences between species and anesthesia-analgesia protocols may explain variable findings [13]. Based upon the increased myofilament calcium sensitivity, impaired diastolic function may ensue. This is indeed confirmed in a recent study that carefully examined the effects of hypothermia on diastolic function in an intact pig model showing a delayed and prolonged active relaxation and a decreased diastolic distensibility. Although the reduced heart rate could be expected to compensate and improve diastolic filling, this is generally not the case because hypothermiainduced heart rate reduction results almost entirely from a prolonged contraction whereas the diastolic interval is virtually unchanged [14].

The complex interplay between intrinsic biophysical and biochemical effects and compensatory physiological changes combined with potentially altered drug responses complicates the management of patients subjected to induced hypothermia in the intensive care unit [15]. The paper by Filseth and colleagues adds new information by reporting on left ventricular function not only during induction of hypothermia, but also during the re-warming and, particularly, the post-hypothermic stage. The findings during mild hypothermia $\left(34^{\circ} \mathrm{C}\right)$ largely confirm previous reports with improved systolic function and depressed diastolic function. However, the authors continued cooling to $25^{\circ} \mathrm{C}$. During induction of severe hypothermia, diastolic function gradually decreased further, but systolic function also started to decrease at this stage. During re-warming, most indices tended to return to baseline values. However, post-hypothermic systolic function remained depressed in contrast to diastolic function, which fully normalized.

The authors are to be complimented for developing an animal model that closely mimics human physiology and by using advanced invasive pressure-volume methods to assess cardiac function. The main conclusions of the paper relate to post-hypothermic circulatory and ventricular function. When trying to translate these findings to the clinical situation, several potential limitations of the study should be mentioned. First, the study was performed in normal, healthy pigs and the direct effects and late consequences of hypothermia may be different in, for example, elderly subjects with depressed left ventricular function. Second, the authors induced severe hypothermia in contrast to mild hypothermia recommended by current guidelines. Third, steady state hypothermia was maintained for only 1 hour, which is very different from, for example, the 12 to 24 hours recommended for comatose post-cardiac arrest patients. Thus, the study clearly provides interesting new data on the effect of temperature on intrinsic ventricular function in a clinically relevant animal model. However, the translation of the findings to post-hypothermic critical care patients warrants further studies.

\section{Competing interests}

The author declares that he has no competing interests.

Published: 9 February 2011

\section{References}

1. Filseth OM, How O-J, Kondratiev T, Gamst TM, Tveita T: Post-hypothermic cardiac left ventricular systolic dysfunction after rewarming in an intact pig model. Crit Care 2010, 14:R211.

2. The Hypothermia After Cardiac Arrest (HACA) study group: Mild therapeutic hypothermia to improve the neurologic outcome after cardiac arrest. NEngl J Med 2002, 346:549-556.

3. Bernard SA, Gray TW, Buist MD, Jones BM, Silvester W, Gutteridge G, Smith K: Treatment of comatose survivors of out-of-hospital cardiac arrest with induced hypothermia. N Engl J Med 2002, 346:557-563.

4. Neumar RW, Nolan JP, Adrie C, Aibiki M, Berg RA, Bottiger BW, Callaway C, Clark RSB, Geocadin RG, Jauch EC, Kern KB, Laurent I, Longstreth WT Jr, Merchant RM, Morley P, Morrison LJ, Nadkarni V, Peberdy MA, Rivers EP, Rodriguez-Nunez A, Sellke FW, Spaulding C, Sunde K, Vanden Hoek T: Postcardiac arrest syndrome: epidemiology, pathophysiology, treatment, and prognostication a consensus statement from the International Liaison Committee on Resuscitation (American Heart Association, Australian and New Zealand Council on Resuscitation, European Resuscitation Council, Heart and Stroke Foundation of Canada, InterAmerican Heart Foundation, Resuscitation Council of Asia, and the Resuscitation Council of Southern Africa); the American Heart Association Emergency Cardiovascular Care Committee; the Council on Cardiovascular Surgery and Anesthesia; the Council on Cardiopulmonary, Perioperative, and Critical Care; the Council on Clinical Cardiology; and the Stroke Council. Circulation 2008, 118:2452-2483.

5. Peberdy MA, Callaway CW, Neumar RW, Geocadin RG, Zimmerman JL, Donnino M, Gabrielli A, Silvers SM, Zaritsky AL, Merchant R, Vanden HoekTL, Kronick SL: Part 9: post-cardiac arrest care: 2010 American Heart Association guidelines for cardiopulmonary resuscitation and emergency cardiovascular care. Circulation 2010, 122:S768-786.

6. Janata A, Holzer M: Hypothermia after cardiac arrest. Prog Cardiovasc Dis 2009, 52:168-179.

7. Lampe JW, Becker LB: State of the art in therapeutic hypothermia. Annu Rev Med 2011, 62:11.1-11.15.

8. Kelly FE, Nolan JP: The effects of mild induced hypothermia on the myocardium: a systematic review. Anaesthesia 2010, 65:505-515.

9. Parham WM, Edelstein KB, Unger BB, Mooney MM: Therapeutic hypothermia for acute myocardial infarction: past, present, and future. Crit Care Med 2009, 37:\$234-237.

10. Koreny M, Sterz F, Uray T, Schreiber W, Holzer M, Laggner A, Herkner H: Effect of cooling after human cardiac arrest on myocardial infarct size. Resuscitation 2009, 80:56-60.

11. Weisser J, Martin J, Bisping E, Maier LS, Beyersdorf F, Hasenfuss G, Pieske B: 
Influence of mild hypothermia on myocardial contractility and circulatory function. Basic Res Cardiol 2001, 96:198-205.

12. Jacobshagen C, Pelster T, Pax A, Horn W, Schmidt-Schweda S, Unsöld BW, Seidler T, Wagner S, Hasenfuss G, Maier LS: Effects of mild hypothermia on hemodynamics in cardiac arrest survivors and isolated failing human myocardium. Clin Res Cardiol 2010, 99:267-276.

13. Chamorro C, Borrallo JM, Romera MA, Silva JA, Balandín B: Anesthesia and analgesia protocol during therapeutic hypothermia after cardiac arrest: a systematic review. Anesth Analg 2010, 110:1328-1335.

14. Post H, Schmitto JD, Steendijk P, Christoph J, Holland R, Wachter R, Schöndube FW, Pieske B: Cardiac function during mild hypothermia in pigs: increased inotropy at the expense of diastolic dysfunction. Acta Physiol 2010, 199:43-52

15. Polderman KH, Herold I: Therapeutic hypothermia and controlled normothermia in the intensive care unit: Practical considerations, side effects, and cooling methods. Crit Care Med 2009, 37:1101-1120.

\section{doi:10.1186/cc9989}

Cite this article as: Steendijk P: Cardiovascular consequences of cooling in critical care. Critical Care 2011, 15:119. 